\title{
Effects of solar activity on noise in CALIOP profiles above the South Atlantic Anomaly
}

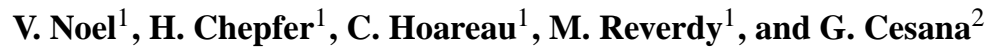 \\ ${ }^{1}$ CNRS, Laboratoire de Météorologie Dynamique UMR8539, Ecole Polytechnique, 91128 Palaiseau, France \\ ${ }^{2}$ Jet Propulsion Laboratory/NASA, Caltech, Pasadena, CA, USA
}

Correspondence to: V. Noel (vincent.noel@1md.polytechnique.fr)

Received: 30 August 2013 - Published in Atmos. Meas. Tech. Discuss.: 27 September 2013

Revised: 9 April 2014 - Accepted: 28 April 2014 - Published: 5 June 2014

\begin{abstract}
We show that nighttime dark noise measurements from the spaceborne lidar CALIOP contain valuable information about the evolution of upwelling high-energy radiation levels. Above the South Atlantic Anomaly (SAA), CALIOP dark noise levels fluctuate by $\pm 6 \%$ between 2006 and 2013, and follow the known anticorrelation of local particle flux with the 11-year cycle of solar activity (with a 1year lag). By analyzing the geographic distribution of noisy profiles, we are able to reproduce known findings about the SAA region. Over the considered period, it shifts westward by $0.3^{\circ}$ year $^{-1}$, and changes in size by $6^{\circ}$ meridionally and $2^{\circ}$ zonally, becoming larger with weaker solar activity. All results are in strong agreement with previous works. We predict SAA noise levels will increase anew after 2014, and will affect future spaceborne lidar missions most near 2020.
\end{abstract}

\section{Introduction}

The South Atlantic Anomaly (SAA) refers to an irregular geographic area, roughly centered on $30^{\circ} \mathrm{W}, 30^{\circ} \mathrm{S}$, over South America and the Atlantic Ocean, where the Earth's geomagnetic field is weakest and the inner radiation belt comes closest to the surface. These conditions arise from the misalignment between the Earth's magnetic and rotational axes and lead to the trapping of ionized particles between 200 and $1600 \mathrm{~km}$ above the surface (Ginet et al., 2007) - mostly protons and electrons but also antiprotons created by the interaction with cosmic rays (Adriani et al., 2011). The resulting increased local particle flux affects spaceborne electronics and detectors travelling within the area.
The Cloud-Aerosol Lidar with Orthogonal Polarization (CALIOP, Winker et al., 2009) orbits the Earth at $705 \mathrm{~km}$ of altitude as part of the CALIPSO payload (Cloud-Aerosol Lidar and Infrared Pathfinder Satellite Observation) in the A-Train constellation (Stephens et al., 2002) and flies over the SAA several times a day. It has been obvious since early CALIOP operation that the SAA strongly affects its nighttime observations of backscatter coefficients (Hunt et al., 2009, H09 hereafter), leading to increased levels of random fluctuations in the observed signal. Due to the increased particle flux, dark noise levels in the $532 \mathrm{~nm}$ channel are 30 times larger over the SAA, leading to a decrease of the nighttime signal-to-noise ratio (SNR) by a factor of 5 (H09).

The noise increase is especially noticeable at stratospheric altitudes, where backscatter returns are weak due to the absence of particles and low molecular densities compared to the troposphere. We performed a quick analysis of CALIOP data for 2008 and found that the standard deviation of stratospheric backscatter at $30-34 \mathrm{~km}$ is consistently 3.2 times larger over the SAA. This has created problems for the calibration of CALIOP signals based on stratospheric signals, which eventually had to ignore measurements over the area (Powell et al., 2009). Studies based on stratospheric CALIOP measurements require careful attention to the issue (e.g., Vernier et al., 2011; Lopes et al., 2013).

Here we document how changes in the intensity and spatial extent of the SAA across seven and a half years (20062013) affect levels of dark noise in CALIOP observations at $532 \mathrm{~nm}$. We show that from those noise levels it is possible to confirm known properties of the SAA and their evolution with time. 

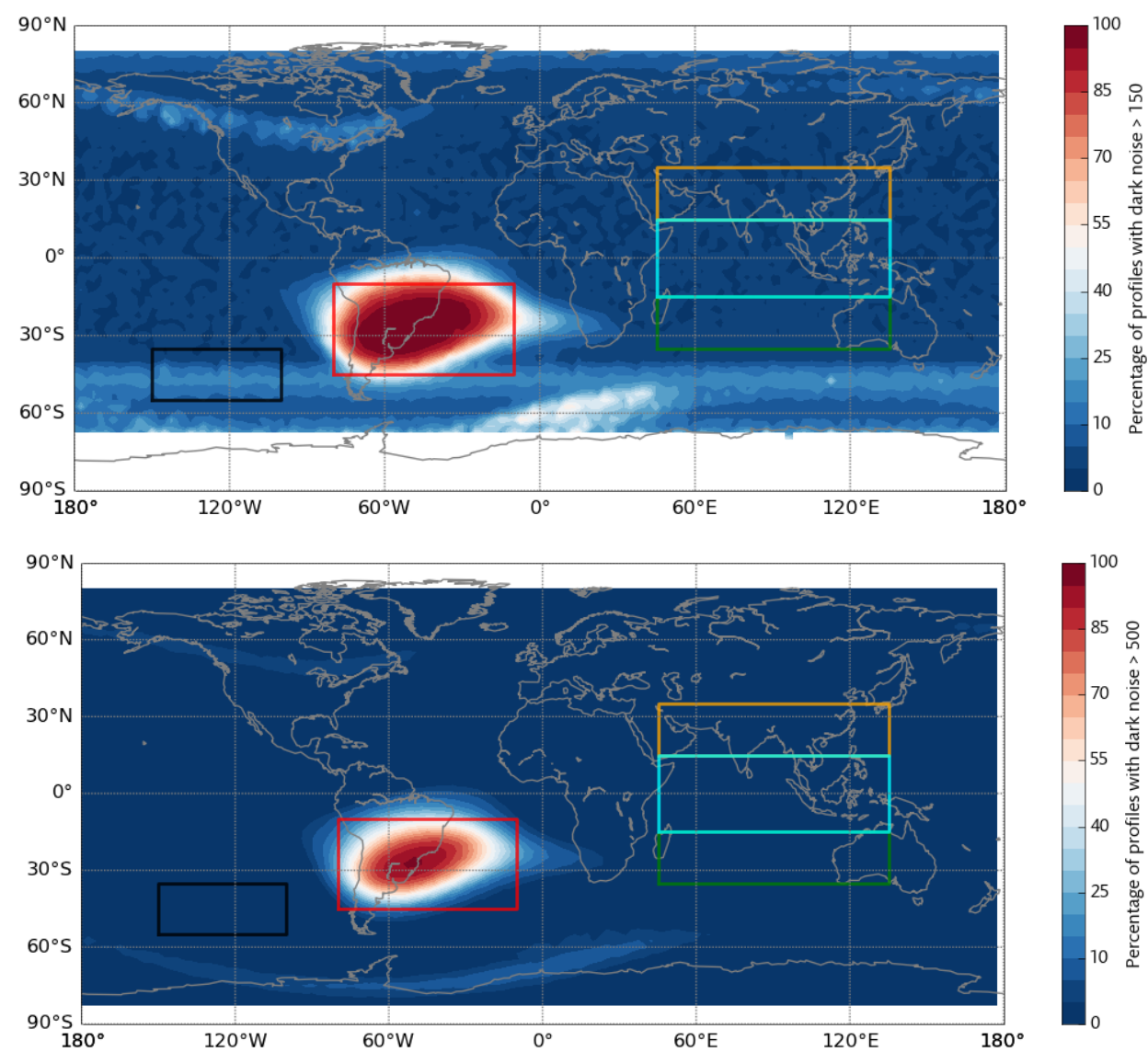

Figure 1. Percentage of profiles at $333 \mathrm{~m}$ horizontal resolution with dark noise above 500 in $2.5^{\circ} \times 2.5^{\circ}$ bins for all 2007 CALIOP nighttime observations. The red box delimits a region affected by the SAA, enclosing all bins with more than $50 \%$ noisy profiles (top left: $80^{\circ} \mathrm{W}, 10^{\circ} \mathrm{S}$, bottom right: $10^{\circ} \mathrm{W}, 45^{\circ} \mathrm{S}$ ), The three boxes between $45^{\circ} \mathrm{E}$ and $135^{\circ} \mathrm{E}$ delimit regions unaffected by any recognized source of increased noise levels, in the Southern Hemisphere $\left(35^{\circ} \mathrm{S}\right.$ to $15^{\circ} \mathrm{S}$, green), the Northern Hemisphere $\left(15^{\circ} \mathrm{N}\right.$ to $35^{\circ} \mathrm{N}$, orange) and around the Equator ( $15^{\circ} \mathrm{S}$ to $15^{\circ} \mathrm{N}$, cyan).

\section{Spatial extent of the SAA}

H09 first mapped the profile-level dark noise in the parallel $532 \mathrm{~nm}$ channel during September and October 2006. They showed how telluric radiation in the SAA induces frequent current spikes and a significant amount of dark noise in CALIOP nighttime measurements. They showed noise is also significant above polar regions, approximately along the aurora ovals, where charged electrons precipitate from the magnetotail, flowing with the geomagnetic field. Finally, noise also increases at high latitudes, near the edges of nighttime orbits, as sunlight becomes scattered above the horizon when the satellite transitions from and to daytime.

Dark noise in CALIOP profiles can be tracked via the Parallel RMS Baseline at $532 \mathrm{~nm}$ variable in CALIOP Level 1 data, which reports in digitizer counts (DCs) the root mean square noise of $100015 \mathrm{~m}$ samples, calculated onboard from the $532 \mathrm{~nm}$ parallel channel in the $65-80 \mathrm{~km}$ altitude range. Since it is unclear how the same variable in the perpendicular channel is affected by the depolarizing properties of the atmosphere and surface below the lidar, we focus here on the parallel channel. H09 showed noise stays below 100 DC in most areas but frequently reaches high levels (>2000 DC) above the SAA.

When using CALIOP observations near the tropopause, it is good practice to filter out profiles with high dark noise levels, which exhibit poor SNR in the upper troposphere. Using a maximum acceptable dark noise of $150 \mathrm{DC}$ (as in, for example, Vernier et al., 2011) effectively removes all observations over the SAA but also in other regions. Our objective here is the opposite: we want to unambiguously identify the SAA region based on its high levels of dark noise and exclude noise from other sources. Figure 1a (top) maps the percentage of individual CALIOP profiles at $333 \mathrm{~m}$ horizontal resolution with noise levels above 150 DC in January 2007. The patterns described by H09 are clear. Over the SAA (red box), more than half of the profiles are affected by noise levels above $150 \mathrm{DC} ; 2-3 \%$ of profiles are affected in the tropics (orange, cyan and green boxes). The aurora ovals show up as wavy patterns at latitudes $50^{\circ}$ and poleward, where 


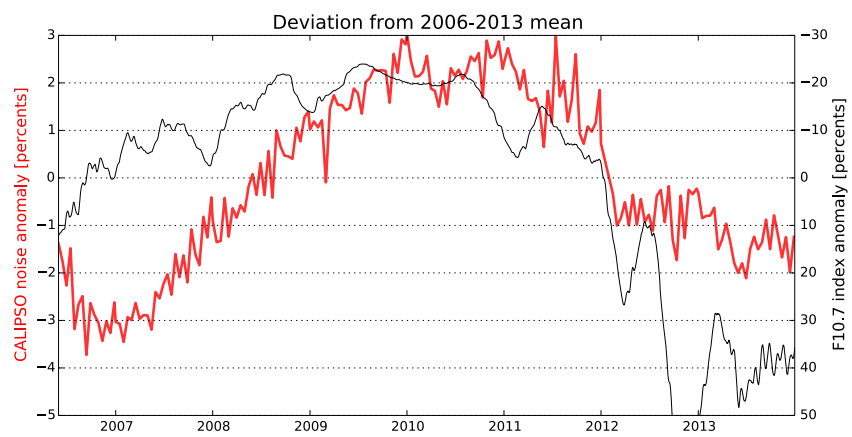

Figure 2. Deviation of the fraction of noisy profiles (dark noise above 500) from the mean over the entire period (49.1\%) in 15day periods between 2006 and 2012 in the SAA region (red box in Fig. 1), delayed by 1 year.

up to $50 \%$ of profiles have noise levels above $150 \mathrm{DC}$. In the Southern Hemisphere (SH), the auroras curve around the SAA region and are not a problem for its detection. Sunlight scattering near the day-night transition, on the other hand, follows a seasonal latitude cycle that brings it near $40^{\circ} \mathrm{S}$ in DJF. It then spreads over the southern border of the SAA (as in Fig. 1a) and becomes a significant problem for its detection. The black box in Fig. 1a delimits a South Pacific region particularly affected by sunlight scattering, but neither by the SAA nor by the polar aurora, where $\sim 10 \%$ of profiles have noise levels above $150 \mathrm{DC}$. Since noise from sunlight scattering originates from photoelectrons, it can be affected by changes in receiver gain efficiency with time, which is susceptible to drift.

A noise threshold of $150 \mathrm{DC}$ is therefore too low to unambiguously identify profiles affected by SAA noise. Unfortunately, high-energy noise spikes affect CALIOP profiles globally (H09). Dark noise above 15000 DC occurs everywhere, if rarely, and it is not possible to identify a range of dark noise values found only over the SAA. We settled for a minimum noise threshold of $500 \mathrm{DC}$, which affects slightly less than $1 \%$ of profiles in the South Pacific region (black box of Fig. 1a) in January 2007, when sunlight scattering is maximum in the SH. Figure 1b maps the percentage of individual CALIOP profiles (as in Fig. 1a) with dark noise above 500 DC in 2007. In the SAA (red box in Fig. 1b), nearly half of the profiles are affected, and in its center all profiles are affected. The general shape of the SAA region and its boundaries does not change much compared to Fig. 1a. The sunlight scattering noise at high latitudes seen in Fig. 1a is not visible anymore. This ensures that changes in gain efficiency will only remotely affect the noise results presented here.

In stark contrast to these clean geographical patterns, the daytime dark noise (not shown) follows the geographic distribution of reflective surfaces - mostly ice sheets, snow surfaces, bright low-level clouds and ice crystals (H09), whose geographic distribution is extremely variable and hard to predict. In a throwback to passive measurements, it is again difficult to separate the effects of clouds and surface in those CALIOP data. We will thus focus here on nighttime observations, which are much less affected by this issue.

\section{Evolution of the SAA}

Figure 2 shows how a fraction of nighttime profiles with high noise levels (Sect. 2) deviate from the mean $(48.9 \%)$ in 15 day windows between June 2006 and December 2013 over the SAA (red box in Fig. 1). We used CALIOP Level 1 files v.3.01, 3.02 and 3.30, which for our intent and purposes are identical. The noisy fraction of profiles is minimum in 2006 (46\%), increases steadily to reach $52 \%$ in 2010 , then undergoes a rather abrupt drop in 2011 that brings it back to 2007 levels in early 2012 and onwards. Literature shows that the local particle flux within the SAA, which impacts the noise in CALIOP observations, is anticorrelated with the 11-year cycle of solar activity (with 1 year lag) (Fürst et al., 2009). This anticorrelation is due to heating of the exo- and thermosphere during maximum solar activity, which leads to a higher neutral density in the altitudes below affected by the SAA (e.g., Qian et al., 2006). This increases the absorption and deflection of trapped particles, resulting in a lower particle flux compared to when the solar activity is minimum (Dachev et al., 1999). Thus during maximum solar activity the flux of energetic particles below CALIOP is smaller. The 1-year lag reflects the time needed for the atmosphere to react to incoming solar energy. The evolution of the F10.7 index, a measure of the solar radio flux at a wavelength of $10.7 \mathrm{~cm}$ frequently used as a proxy of solar activity, is shown in Fig. 2 with a 1-year lag using an inverted vertical axis to demonstrate the anticorrelation.

CALIOP began operating in 2006, during the downward section of solar cycle 23 , when solar activity was already quite low compared to its 2000 maximum. It kept decreasing until 2009, while CALIOP noise levels over the SAA increased until 2010 due to the 1-year lag. Since then, solar cycle 24 has begun and solar activity has been increasing again, while noise in the SAA region decreased accordingly. The solar cycle is not symmetric: the increase in solar activity is faster ( $\sim 3$ years) than the decrease, which shows an opposite influence on noise levels (Fig. 2). We should thus expect the SAA noise to reach its minimum in the near future (probably in 2014), and resume a slow increase until 1 year after the next minimum of solar activity, in 2020. CALIOP will unfortunately be inoperative at this point, but it seems safe to assume that future spaceborne lidar missions will be similarly affected.

Since all profiles are noisy in the SAA center (Fig. 1b) and the total number of noisy profiles in the SAA region changes with time (Fig. 2), the affected surface must change with time. Meridionally (Fig. 3, top) the SAA stayed roughly centered around $25^{\circ} \mathrm{S}$, and more-or-less symmetrical except its north boundary shifted towards the Equator as the number 

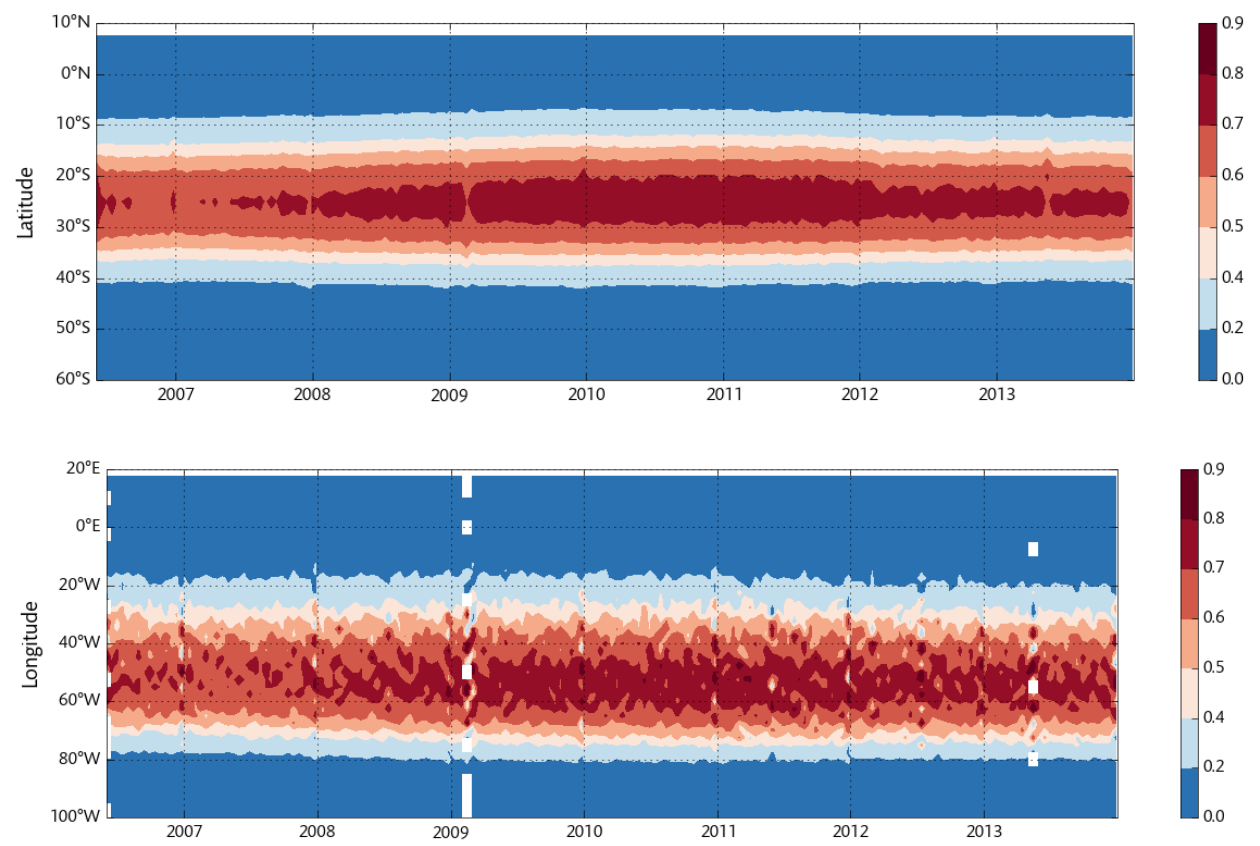

Figure 3. Evolution with time of the fraction of noisy profiles ( $333 \mathrm{~m}$ horizontal resolution) as a function of latitude between $70^{\circ} \mathrm{W}$ and $30^{\circ} \mathrm{W}$ (top) and longitude between $40^{\circ} \mathrm{S}$ and $10^{\circ} \mathrm{S}$ (bottom). White boxes in the bottom figure are due to missing data.

of noisy profiles increased. The south boundary meanwhile appears constant, although it is weakly disturbed by the seasonal irruption (in December-January) of sunlight scatter. Zonally (Fig. 3, bottom), the SAA is less symmetrical, with a longer tail extending towards Africa. Its west boundary extended westwards until 2010, but narrowed primarily from the east after 2011. This translates into a slight westwards shift of the SAA between 2006 and 2013.

To better describe these changes, for each month we retrieved the region where at least $10 \%$ of profiles are affected by dark noise levels above 500. Figure 4 (top) shows this region widened zonally from $72^{\circ}$ in 2006 to $76^{\circ}$ in 2010 2012 , when it began shrinking again down to $\sim 70^{\circ}$. This behavior can be attributed first to a significant westward extension of the west boundary (Fig. 4, second row) until 2010 (to $\sim 84^{\circ} \mathrm{W}$ ), followed by a westward shift of the east boundary (third row) after 2011 , from $8^{\circ} \mathrm{W}$ to $12^{\circ} \mathrm{W}$. Meanwhile, the maximum fraction of noisy profiles (Fig. 4, bottom) moved from $50^{\circ} \mathrm{W}$ in 2006 to $52^{\circ} \mathrm{W}$ in 2013 , a westward shift of $0.3^{\circ}$ year $^{-1}$ (average residual $1.27^{\circ}$ ). This result agrees very well with previous works (e.g., Fürst et al., 2009, references $0.27^{\circ}$ year $^{-1}$ ), even if the anticorrelation with solar activity probably affects the regression. From a meridional point of view, the region where more than $10 \%$ of profiles are affected by dark noise levels above 500 widened by a little more than $2^{\circ}$ between 2006 and 2010 (Fig. 5, top), when it began shrinking again down to 2006 levels. This change is mainly attributable to an equatorward displacement of the north boundary of the SAA (Fig. 5, second row) from $4^{\circ} \mathrm{S}$ to almost $2^{\circ} \mathrm{S}$. The south boundary appears more stable (Fig. 5, third row), although its retrieval from CALIOP values is complicated by the increase in solar scattering near $40^{\circ} \mathrm{S}$ in DJF. The maximum fraction of noisy profiles appears to follow the change in size described above, moving north until 2010-2011 and going south afterwards. An almost halfdegree dip is seen near the end of 2007, when the CALIOP laser was pointed away from the nadir to avoid specular reflection on horizontally oriented crystals - that change put the footprint position slightly south of the actual satellite latitude.

\section{Large noise levels in clear areas}

In tropical areas outside the SAA, supposedly unaffected by any known source of additional noise (non-SAA boxes in Fig. 1), only a very small fraction of profiles $(<0.1 \%)$ are affected by noise levels above 500 . This fraction still appears anticorrelated with solar activity (Fig. 6): noise levels are slightly stronger from mid-2008 to 2012, just like over the SAA (Fig. 2). The increase is however extremely weak compared to above the SAA. Figure 6 also reveals that noise levels in all three regions are affected by an underlying yearly cycle, which is minimum in July and maximum in January. Surprisingly, this cycle similarly affects both hemispheres with the season, and thus appears unrelated to the amount of incoming solar light reaching a particular hemisphere. Peaks appear more spiky in the SH (green) and smoother in the NH (orange). Noise levels in the SAA region are probably affected by a similar cycle, but the effect is too weak 

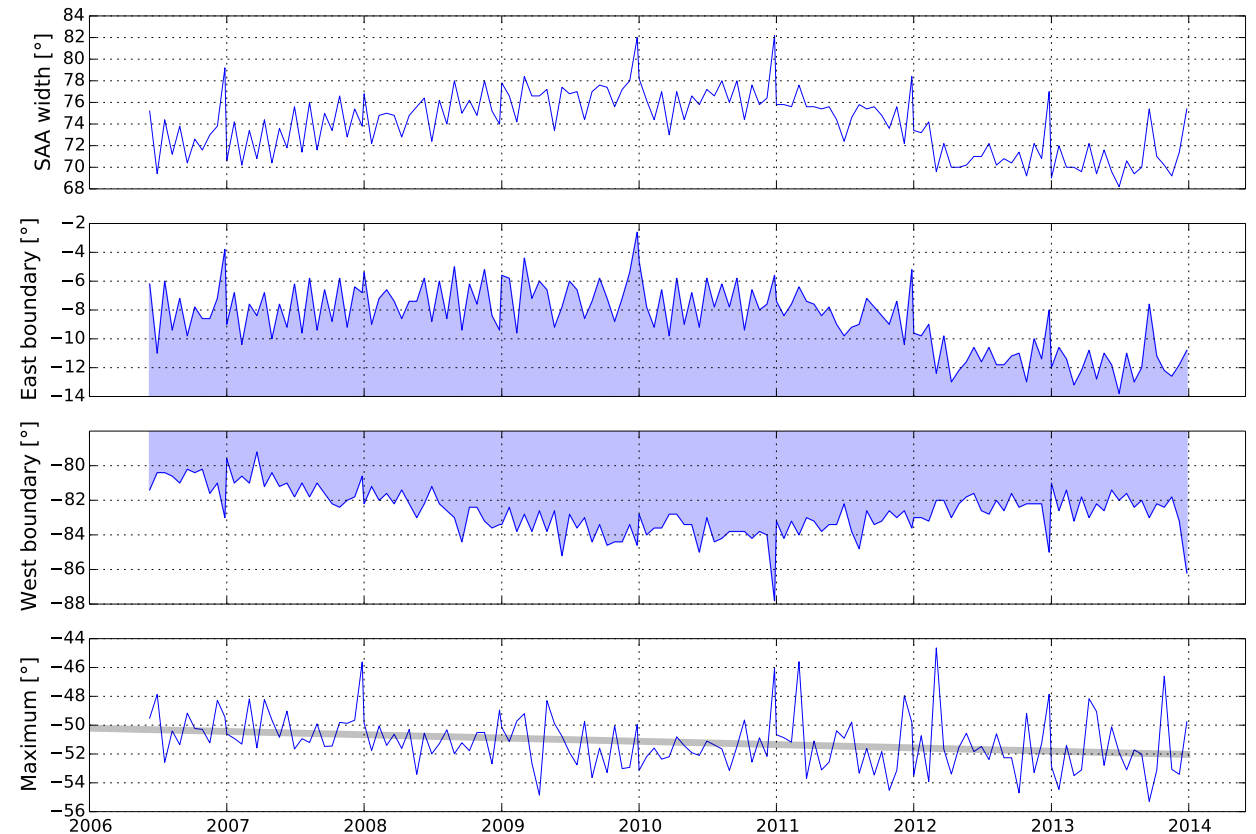

Figure 4. (top) zonal width of the SAA, defined as the region where more than $10 \%$ of profiles between $45^{\circ} \mathrm{S}$ and $10^{\circ} \mathrm{S}$ are affected by large noise. (second and third rows) east and west boundaries of the region. (bottom) longitude of the maximum fraction of noisy profiles, with a linear regression in grey.
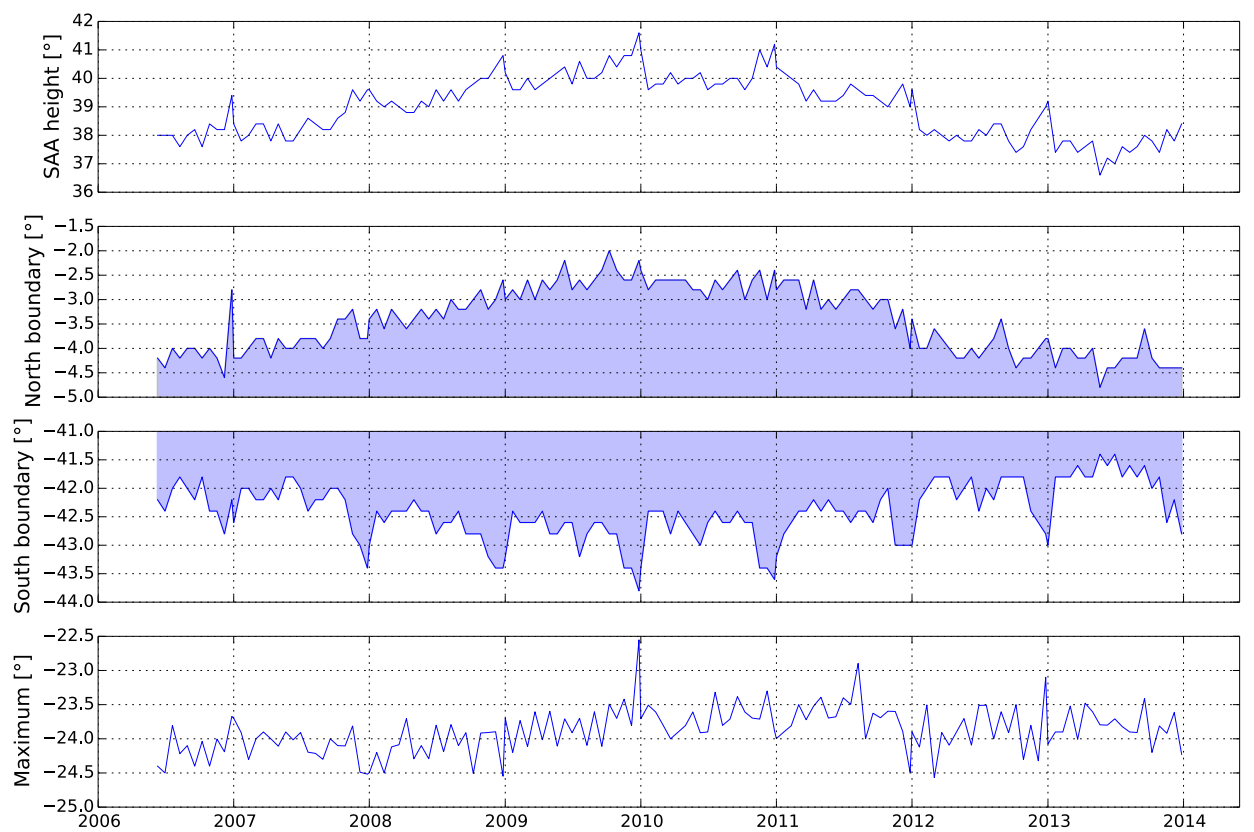

Figure 5. (top) meridional height of the SAA, defined as the region where more than $10 \%$ of profiles between $80^{\circ} \mathrm{W}$ and $10^{\circ} \mathrm{W}$ are affected by large noise. (second and third rows) north and south boundaries of the region. (bottom) latitude of the maximum fraction of noisy profiles.

compared to the impact of the 11-year solar cycle to register in Fig. 2. This yearly cycle bears a strong resemblance to the temperature cycle of the photomultiplier tubes (PMTs) of the telescope detectors at $532 \mathrm{~nm}$, driven by the varying distance to the sun. While it is not possible to totally rule out the influence of changes in the radiation environment, the witnessed noise fluctuations in clear areas are more likely driven by changes in instrument characteristics. Fortunately, the amount of profiles affected by large noise in clear regions stays very low $(0.3-0.4 \%)$. Generic CALIOP retrievals of 


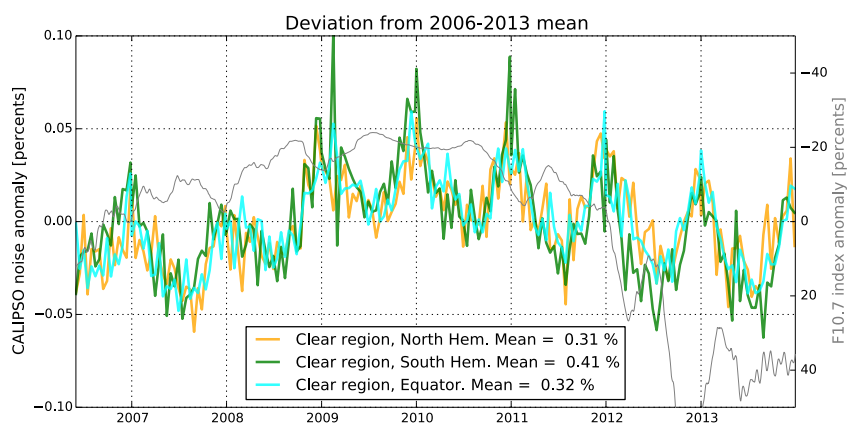

Figure 6. Same as Fig. 2, in areas supposedly unaffected by sources of additional noise (orange, green and cyan boxes in Fig. 1). The grey line shows the deviation of the F10.7 index delayed by 1 year (as in Fig. 2) for reference.

atmospheric properties are not likely to be influenced by such rare occurrences. Perhaps more importantly, the fluctuations of noise levels with time are even smaller $(<0.1 \%)$ and any impact on CALIOP retrievals should stay relatively constant.

\section{Summary}

We found that noise in CALIOP nighttime profiles above the South Atlantic Anomaly is influenced by the 11-year cycle of solar activity. We documented how the size of this area has changed by $6^{\circ}$ zonally and $2^{\circ}$ meridionally in the past 7 years, widening until 2011 and shrinking afterwards. The SAA center shifted to the west by $0.3^{\circ}$ year ${ }^{-1}$. Even if variations in instrument characteristics cannot be ruled out as driving these changes, the agreement with previous studies suggests they are likely driven by changes in the Earth's radiation environment. Studies using CALIOP observations in the stratosphere and upper troposphere close to Central and South America should be mindful of the increased noise levels occurring in 2010-2011. SAA noise levels will likely increase soon, affecting upcoming spaceborne lidars most near 2020. Finally, even in areas devoid of solar scattering, CALIOP nighttime noise levels are weakly influenced by the solar cycle, modulated by a yearly cycle most likely driven by changes in the telescope PMT temperature with the distance to the sun. Large noise levels in those areas are however extremely rare.

Acknowledgements. The authors wish to thank the NASA Langley CALIOP team for the CALIOP data, the ICARE data center for access to the data, and ClimServ for providing computing facilities. They also thank J.-P. Vernier for pointing them to the Parallel_RMS_Baseline_532 variable. They thank all reviewers, among them W. Hunt, for useful comments and feedback. Data analysis was conducted using Python and Numpy (Oliphant, 2007). Figures were created using Matplotlib (Hunter, 2007).

Edited by: C. von Savigny

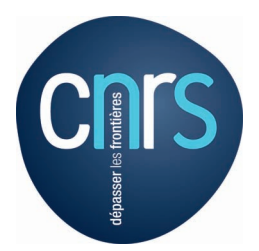

The publication of this article is financed by CNRS-INSU.

\section{References}

Adriani, O., Barbarino, G. C., Bazilevskaya, G. A., Bellotti, R., Boezio, M., Bogomolov, E. A., Bongi, M., Bonvicini, V., Borisov, S., Bottai, S., Bruno, A., Cafagna, F., Campana, D., Carbone, R., Carlson, P., Casolino, M., Castellini, G., Consiglio, L., De Pascale, M. P., De Santis, C., De Simone, N., Di Felice, V., Galper, A. M., Gillard, W., Grishantseva, L., Jerse, G., Karelin, A. V., Kheymits, M. D., Koldashov, S. V., Krutkov, S. Y., Kvashnin, A. N., Leonov, A., Malakhov, V., Marcelli, L., Mayorov, A. G., Menn, W., Mikhailov, V. V., Mocchiutti, E., Monaco, A., Mori, N., Nikonov, N., Osteria, G., Palma, F., Papini, P., Pearce, M., Picozza, P., Pizzolotto, C., Ricci, M., Ricciarini, S. B., Rossetto, L., Sarkar, R., Simon, M., Sparvoli, R., Spillantini, P., Stozhkov, Y. I., Vacchi, A., Vannuccini, E., Vasilyev, G., Voronov, S. A., Yurkin, Y. T., Wu, J., Zampa, G., Zampa, N., and Zverev, V. G.: The discovery of geomagnetically trapped cosmicray antiprotons, Astrophys. J. Lett., 737, L29, doi:10.1088/20418205/737/2/L29, 2011.

Dachev, T. P., Tomov, B. T., Matviichuk, Y. N., Koleva, R. T., Semkova, J. V., Petrov, V. M., Benghin, V. V., Ivanov, Y. V., Shushakov, V. A., and Lemaire, J. F.: Solar cycle variations of MIR radiation environment as observed by the LIULIN dosimeter, Radiat. Meas., 30, 269-274, 1999.

Fürst, F., Wilms, J., Rothschild, R. E., Pottschmidt, K., Smith, D. M., and Lingenfelter, R.: Temporal variations of strength and location of the South Atlantic Anomaly as measured by RXTE, Earth Planet. Sci. Lett., 281, 125-133, 2009.

Ginet, G. P., Madden, D., Dichter, B. K., and Brautigam, D. H.: Energetic Proton Maps for the South Atlantic Anomaly, in: Radiation Effects Data Workshop, IEEE, 1-8, 2007.

Hunt, W. H., Winker, D. M., Vaughan, M. A., Powell, K. A., Lucker, P. L., and Weimer, C.: CALIPSO lidar description and performance assessment, J. Atmos. Ocean. Tech., 26, 1214-1228, 2009.

Hunter, J. D.: Matplotlib: A 2D graphics environment, Comput. Sci. Eng., 9, 90-95, 2007.

Lopes, F. J. S., Landulfo, E., and Vaughan, M. A.: Assessment of the CALIPSO Lidar $532 \mathrm{~nm}$ version 3 lidar ratio models using a ground-based lidar and AERONET sun photometers in Brazil, Atmos. Meas. Tech. Discuss., 6, 1143-1199, doi:10.5194/amtd6-1143-2013, 2013.

Oliphant, T. E.: Python for Scientific Computing, Comput. Sci. Eng., 9, 10-20, 2007.

Powell, K. A., Hostetler, C. A., Vaughan, M. A., Lee, K.-P., Trepte, C. R., Rogers, R. R., Winker, D. M., Liu, Z., Kuehn, R. E., Hunt, W. H., and Young, S. A: CALIPSO Lidar Calibration Algorithms, Part I: Nighttime 532-nm Parallel Channel and 532-nm Perpendicular Channel, J. Atmos. Oceanic Technol., 26, 2015, 2015-2033, doi:10.1175/2009JTECHA1242.1, 2009.

Qian, L., Roble, R. G., Solomon, S. C., and Kane, T. J.: Calculated and observed climate change in the thermosphere, and a 
prediction for solar cycle 24, Geophys. Res. Lett., 33, L23705, doi:10.1029/2006GL027185, 2006.

Stephens, G. L., Vane, D. G., Boain, R. J., Mace, G. G., Sassen, K., Wang, Z., Illingworth, A. J., O'Connor, E. J., Rossow, W. B., Durden, S. L., Miller, S. D., Austin, R. T., Benedetti, A., Mitrescu, C. and Team, T. C. S.: The Cloudsat Mission and the A-Train, Bull. of the Am. Met. Soc., 83, 1771-1790, 2002.
Vernier, J.-P., Thomason, L. W., and Kar, J.: CALIPSO detection of an Asian tropopause aerosol layer, Geophys. Res. Lett., 38, L07804, doi:10.1029/2010GL046614, 2011.

Winker, D. M., Vaughan, M. A., Omar, A., Hu, Y., and Powell, K. A.: Overview of the CALIPSO mission and CALIOP data processing algorithms, J. Atmos. Ocean. Tech., 26, 2310-2323, 2009. 